\title{
Magnetic Field Effects on 4G Positions in Shielded Metal Arc Welding Process
}

\author{
NurAzida CheLah, Muhamad Hellmy Hussin
}

\begin{abstract}
With the advancement of welding techniques, Arc-welding is one of the most commonly and widely used welding technique for variety of purposes. The underside of welding to be performed makes the molten pool going downward because of gravity vector pulling affects the molten pool. The main purpose of this study is to study how the molten of electrode produced reduce on going downward and produce a good root fusion in overhead position of welding in single $V$-butt joint with the help of magnetic field on the workpiece. The study of magnet characteristic which includes thebehaviour of molten pool toward magnetic field, the macrostructure and microstructure and its strength should be carried out. Each magnet strength has their own characteristics that affects toward weldment on base metal.As a result, it can be concluded that having a magnetic field applies on base metal A36 low carbon steel may reduce the molten pool from going downward. The selection of a correct magnet strength and welding process may produce good and quality weldment especially in terms of its weld properties and geometry.
\end{abstract}

Index Terms: magnetic field, molten pool, low carbon steel, gravity, microstructure.

\section{INTRODUCTION}

Shield Metal Arc Welding (SMAW), often referred by most welders in the field as stick electrode welding or Manual Metal Arc (MMA), which is one of the most widely used welding processes in the fabrication and repair of metals. Its popularity has resulted from the development of flux covered electrodes capable of making welds having physical properties that are equal or superior to the material being welded. SMAW is a welding process that uses shielding to protect the weld from contamination. It is one of the most common arc welding processes in the world because of its simplicity, versatility, affordability, and suitability for most applications. To begin the arc, the tip of the electrode is struck onto the base metal or workpiece and hold onto the gap/ length between both tips and base metal. Two types of electrode used in the Arc Welding, consumables and non-consumables. For consumables, it is often in the form of wire or rod, either coated with flux or non-coated [1]. Additionally, SMAW welding process is most widely used in

Revised Manuscript Received on February 21, 2020.

* Correspondence Author

NurAzida CheLah*, Fabrication \& Joining, University of Kuala Lumpur Malaysia France Institute (UNIKL MFI), Selangor, Malaysia.

Muhamad Hellmy Hussin, Fabrication \& Joining, University of Kuala Lumpur Malaysia France Institute (UNIKL MFI), Selangor, Malaysia.

(C) The Authors. Published by Blue Eyes Intelligence Engineering and Sciences Publication (BEIESP). This is an open access article under the CC BY-NC-ND license (http://creativecommons.org/licenses/by-nc-nd/4.0/) shipbuilding and construction industries to transport the important fluids, such as, water and oil. Even though the circumferential welding process is very significant in many industrial fields, installation of a circumferential welding automation system is challenging because it requires the accurate seam-tracking equipment, precise pipeline alignment, and optimization of welding parameters. Among several difficulties faced, the optimization of welding parameters in circumferential welding requires an enormous effort to obtain the sound and uniform weld beads owing to the various effects of gravity in different welding positions [2].

There are four types of basic welding position which is flat, horizontal, vertical and overhead position. Overhead position is the most difficult and complicated to be performed than the other position. It is named as 4G, 4 means overhead and $\mathrm{G}$ for groove weld. In this welding position, the welding is performed from the underside of a joint. Welding position of $4 \mathrm{G}$ plates are applicable in the fabrication and installation of tanks, vessel, structural, shipbuilding and aeronautics. On the other hand, 4G positions are somehow difficult to perform in getting a good root fusion compared to flat position. The underside of welding shows a high tendency for the molten pool going downward because of gravity vector pulling affects the molten pool. Besides that, the molten pool flow to the weldment is insufficient to make a fully penetrated weld bead in $4 \mathrm{G}$ position. The gravity force draws the molten pool to the downward of the weld, then causing a narrower bead width and higher reinforcement than that formed in flat position [3-5].

A magnet is a material that produces a field force. This magnetic field can't be seen by optic but is liable for notable property of magnet that its strength that pulls on different magnetic attraction materials, such as iron which attracts or repels different magnet. Permanent magnets area created from "hard" ferromagnetic materials like alnico and ferrite that produced from process in an exceedingly powerful magnetic force from manufacture. In order to demagnetize a magnet, a certain magnetic field should be applied wherever this threshold depends on coercivity of the precise material. "Hard" materials have high coercivity, where "soft" materials have low coercivity [6,7]. A transverse magnetic field deflects the arc within welding direction, whereas a longitudinal magnetic field deflects the arc perpendicular to the bead. If the unidirectional magnetic field is enforced to an alternative current or applied to a direct current, then the arc will be fluctuate within position normal to the direction of welding. A magnetic field eternally applied to the welding arc deflects the arc by electromagnetic force within the plane normal to the field lines. 


\section{Magnetic Field Effects on 4G Positions in Shielded Metal Arc Welding Process}

The magnetic field exerts disturbance on the electrons and ions within the arc, which causes the arc to be diverted away from the typical arc lane [8]. The welding arc will be deflected forward, backward, or sideaways with respect to direction of electrode and diverted upon the direction of an external magnetic field. The strength of a magnetic field is defined as the density of magnetic field lines. The strength of magnetic field from welding process was found to decrease with increasing the distance between the magnet and the weld area.

Ferrite magnets are sintered permanent magnets composed of Barium or Strontium Ferrite. This class of magnets, aside from good resistance to demagnetization, has the popular advantage of low cost. Ferrite magnets are very hard and brittle, and require specialized machining techniques. Moreover, they should be machined in an unmagnetized state. There are equipped to machine these materials to specifications. Anisotropic grades are oriented in the manufacturing direction, and must be magnetized in the direction of orientation. Isotropic grades are not oriented and can be magnetized in any direction, although some degree of greater magnetic strength will be found in the pressing dimension, usually the shortest dimension. Permanent magnets can be made in most any shape imaginable. They can be made into round bars, rectangular bars, horseshoes, rings or donuts, disks, rectangles, multi-fingered rings, and other custom shapes. Some are cast into a mold and require grinding to achieve final dimensions. Others start as a powder which is pressed into a mold or pressure bonded or sintered [9-12].

Accordingly, the current paper presents the characteristics of magnetic field of ferrite magnet and how it influenced the molten pool in $4 \mathrm{G}$ position using SMAW process. The microstructure and mechanical properties of the weld joint influenced by the magnetic field were also determined in this study.

\section{MATERIALS AND METHODS}

\section{A. Material Preparation}

ASTM A36 plate is low carbon steel that exhibits good strength coupled with formability which has 58,000 - 80,000 psi (400-500 MPa) for ultimate tensile strength. It is easy to machine and fabricate and can be securely welded. For this experiment used:

i. Twelve specimens of low carbon steel were used.

ii. Size of specimens is $200 \mathrm{~mm} \times 100 \mathrm{~mm} \times 6 \mathrm{~mm}$.

iii. Three different strength of magnet bar (1400, 1600, 1800 gauss)

The composition of A36 low carbon steel is shown in Table 1.

Table 1 Element compositions in wt\% of low carbon steel

\begin{tabular}{|c|l|l|l|l|l|l|}
\hline $\mathbf{C}$ & $\mathbf{S i}$ & $\mathbf{S}$ & $\mathbf{C u}$ & $\mathbf{M n}$ & $\mathbf{P}$ & $\mathbf{F e}$ \\
\hline 0.29 & 0.28 & 0.05 & 0.20 & 1.03 & 0.04 & 98.0 \\
\hline
\end{tabular}

\section{B. Welding Parameters and Visual Inspection}

The butt joint is used for this experiment with $6 \mathrm{~mm}$ thickness. Materials will be joined using Shielded Metal Arc Welding process with different filler metals which are electrode 7016 and 7018. During welding, the magnet will be put on the base metal. Twelve specimens will be weld with magnet on $4 \mathrm{G}$ position and three specimens will be weld without magnet on $1 \mathrm{G}$ position as shown in Fig. 1.

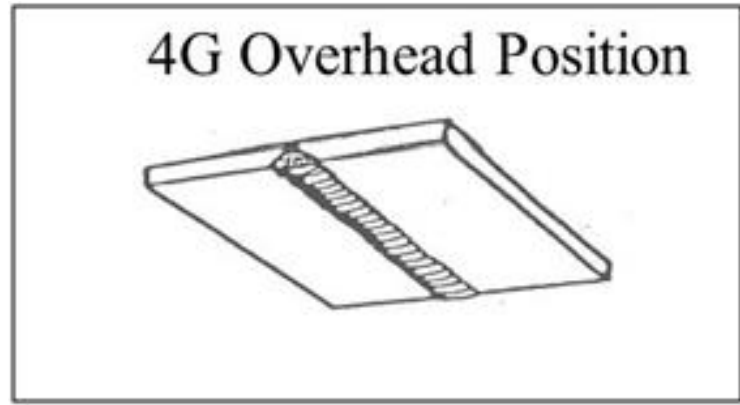

Fig. 1 Groove welding 4G overhead position

\section{Mechanical Testing and Morphology Analysis}

The test specimen will be conducted to compare the difference on mechanical properties with and without magnet.The tensile, bendtest and microstructure analysis will be conducted. The samples also subjected to hardness test using micro-vickers testing machine. The sample were subjected to polishing process from 240 to 1200 sand paper gradesand etched for macro and microstructure analysis.

\section{RESULTS AND DISCUSSION}

\section{A. Magnetic Characteristics Observation}

Fig. 2 shows the magnet characteristics of 1400 gauss magnet strength applied on A36 low carbon steel plate during welding. Since welding involves high heat to fuse the material, and when the ferrite magnet become more resistant to demagnetization when heated, the magnet were place oppositely between the weld area. Even this magnet can be used up to $250{ }^{\circ} \mathrm{C}$, the high temperature from welding can cause the magnet weak or reduce its own strength. Because of magnetic field applies, it show that only a few formation of the mixture metal powder and lubricant oil that concentrated at the weld area. From this situation, a bit of concentrated magnet powder against this magnet shows that the magnetic field on the weld area is not much which makes the welding approximately as the same as in normal welding condition. The high content of magnetic field on the base metal can cause the arc blow or unstable arc. Fig. 3and 4 shows the weld characteristics that are subjected to1600 and 1800 gauss magnet strength applied on A36 low carbon steel plate. The similar observation was found on this sample which is much more equal to the sample that subjected to 1400 gauss magnet as shown in Fig. 2. It shows that the magnetic field on the weld area still did not show much difference and it shows that the welding process applied results was the same as in normal welding condition. It also shows that the characteristics effects from the blow or unstable arc. In this Fig. 2, it also shows that the viscosity of mixture metal powder and lubricant oil concentrated at the weld area start to form the melting action toward gravity force which melted in three points of location. This condition shows that the weld area for this magnet has a moderate magnetic field which makes the weld is in moderate level influenced by magnetization.

Published By:

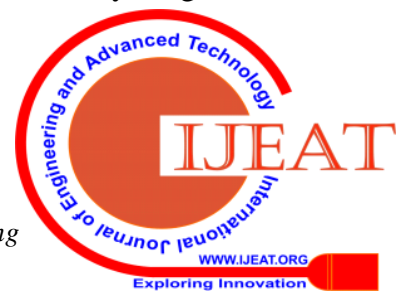




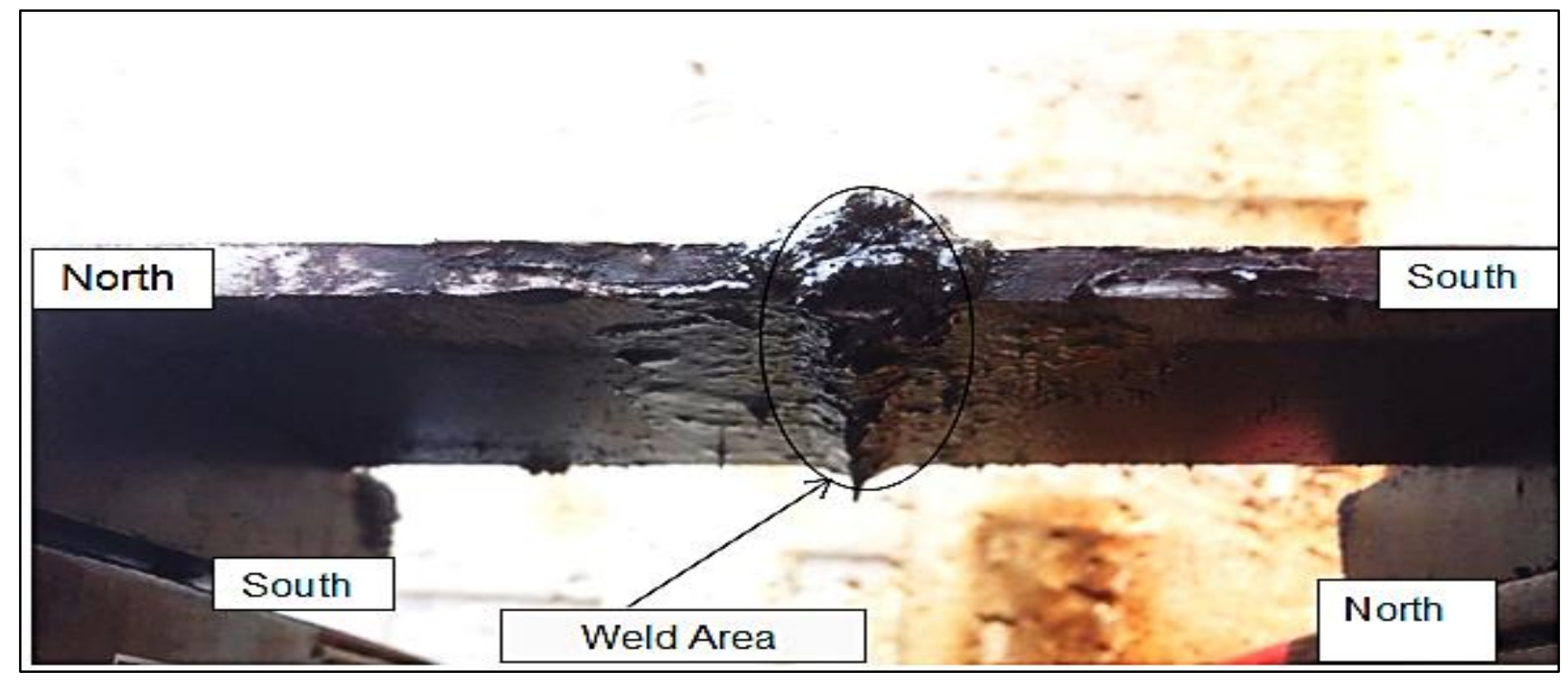

Fig. 2 Welded joint characteristics of using 1400 gauss specimen

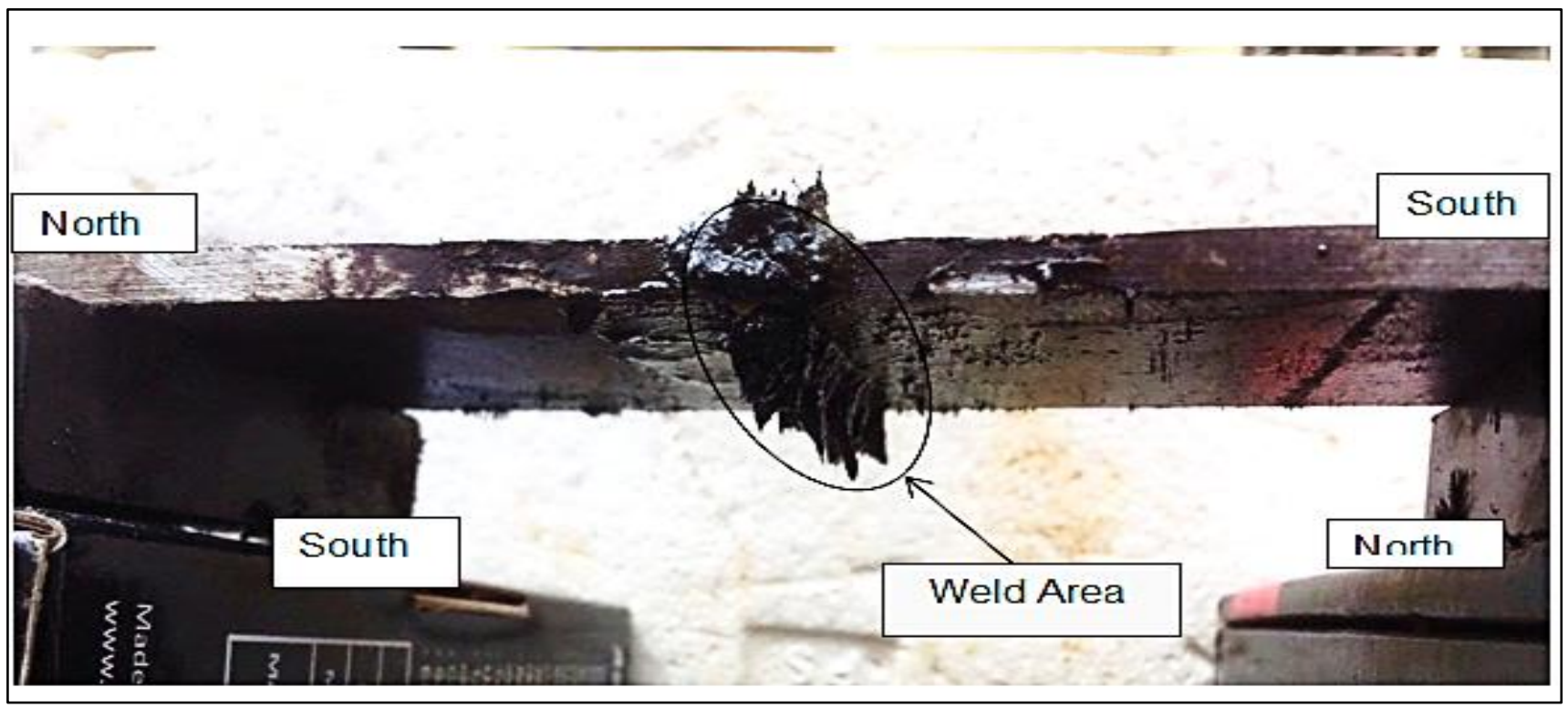

Fig. 3Welded joint characteristics of using 1600 gauss specimen

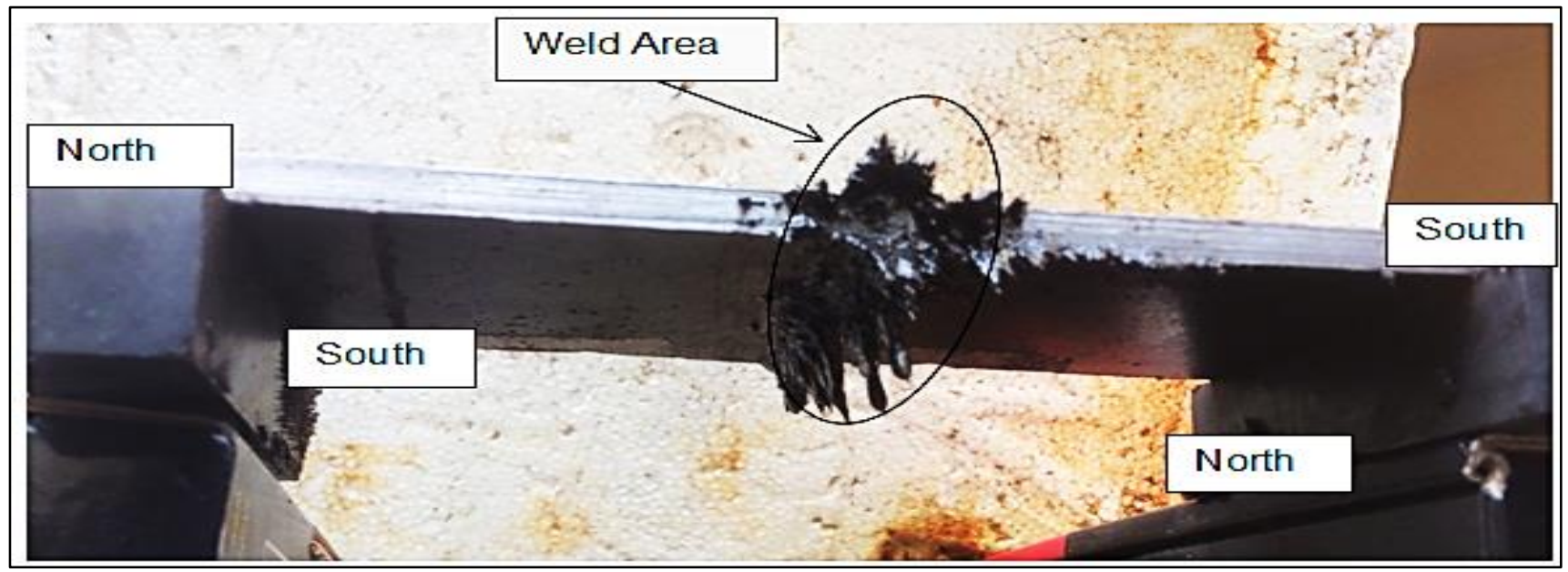

Fig. 4Welded joint characteristics of using 1800 gauss specimen

Published By:

696 Blue Eyes Intelligence Engineering \& Sciences Publication

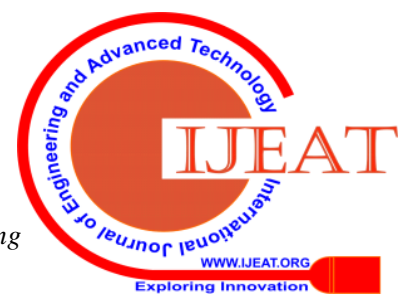




\section{Magnetic Field Effects on 4G Positions in Shielded Metal Arc Welding Process}

\section{B. Molten Pool}

Fig. 5 shows the molten pool occurred during the weldment of using SMAW process. As discussed earlier, welding on 4G position involves high heat to fuse the material, therefore, high stresses was suggested to distribute and generate along the way of the weldment. Because of the gravity pulling the pool downward, stresses of controlling the pool would be much more difficult during welding. There are several kinds of weld pool formation and in this case the formation was a bit different because of the appliedmagnet. Fig. 5 shows during welding a welded sample using 1400 gauss magnet applied on base metal, it shows that there is a centre of pool that flows to the right and left of the base metal in constant direction. The flow of the molten pool help the weldment in order to push the pool upward and then fused throughout the root face. Therefore, the root penetration on the first layer of welding developed in good condition and controlling of the molten pool behaviour become easier [13].

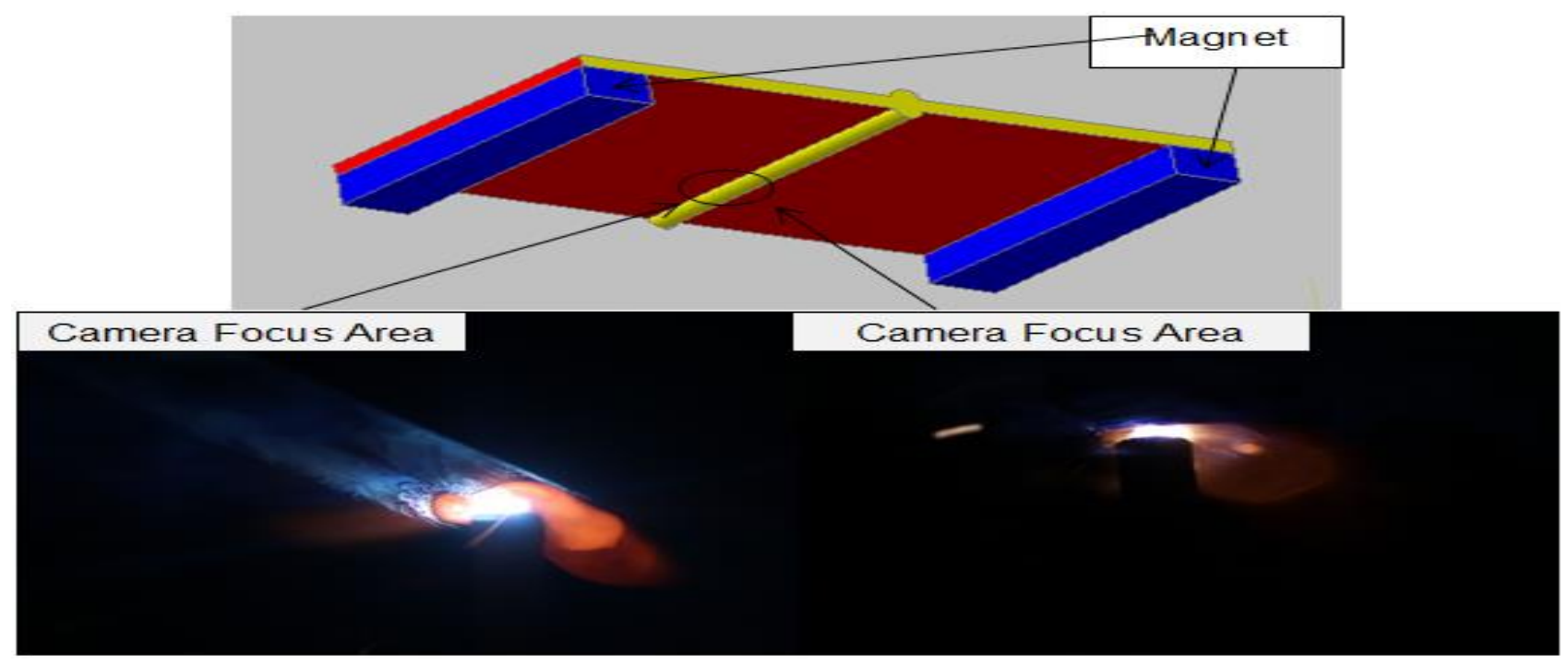

Fig. 5Camera view during welding A36 plate using 1400 gauss magnet

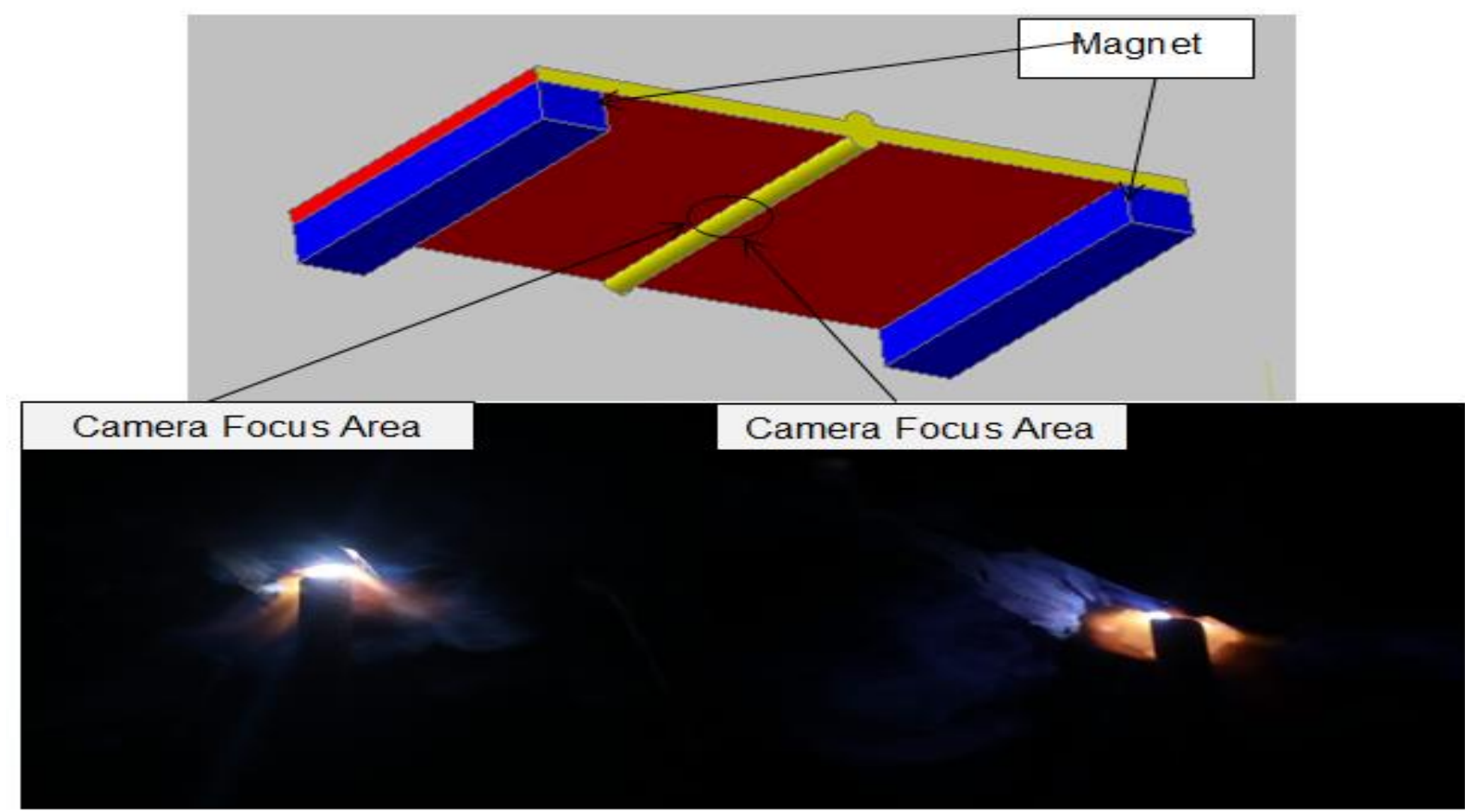

Fig. 6Camera view during welding A36 plate using 1600 gauss magnet

Fig. 6 shows the molten pool occurred during welding.It shows that when the metal experienced high temperature condition and definitely, there are stresses distributed along the weldment. For sample using 1600 gauss magnet applied on base metal, the pool formation flow around the center of the deposited weld only. Meanwhile, as shown in Fig. 8,

when a 1800 gauss magnet applied on base metal, the pool formation flow around the center of deposited weld become smaller than that occurred for sample using a 1600 gauss.

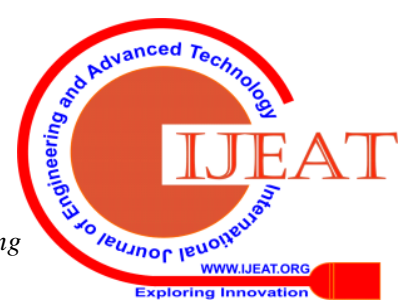


During welding, the controlling of arc become more difficult because of the arc blow situation affected by the strength of the magnet applied.Additionally, the arc was found not stable during the weld run. In this case, even the magnet helps to resist the force of gravity but the strength of the magnet itself interrupt the weld pool formation. Instead of that, it also affects the weld pool shape and its microstructure as well.

According to Figs. 5, 6 and 7, it shows that gravity mainly acts on the melted pool shape and because of that the forces drive the fluid flow. The thermal field and its gravitational forces that acts on the molten pool drives the pool and pulling the pool shape downward and this affects its weld shape and its configuration [14].

When magnet applied during welding, due to the magnetic field externally applied to the welding arc, it deflects the arc by electromagnetic force in the plane normal to the field lines.

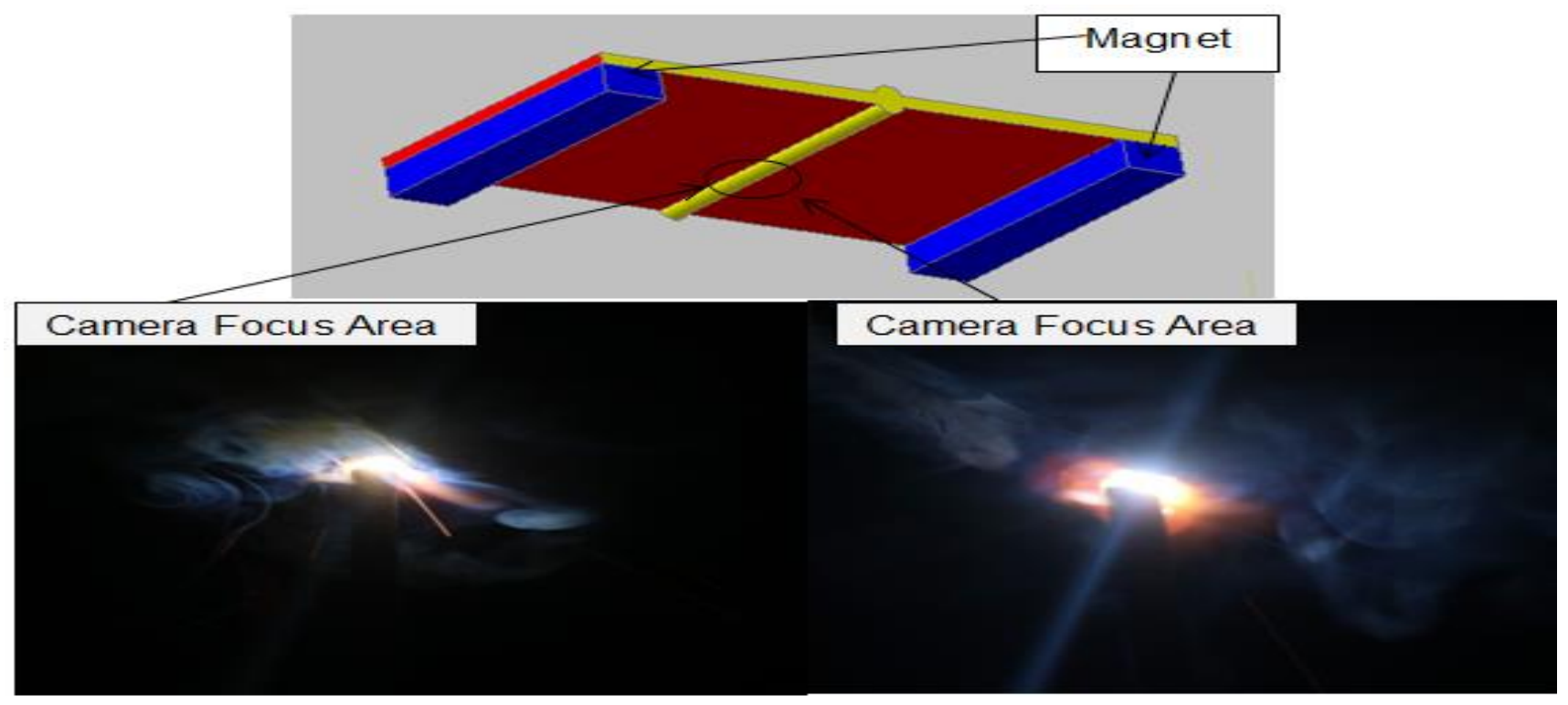

Fig. 7Camera view during welding A36 plate using 1800 gauss magnet

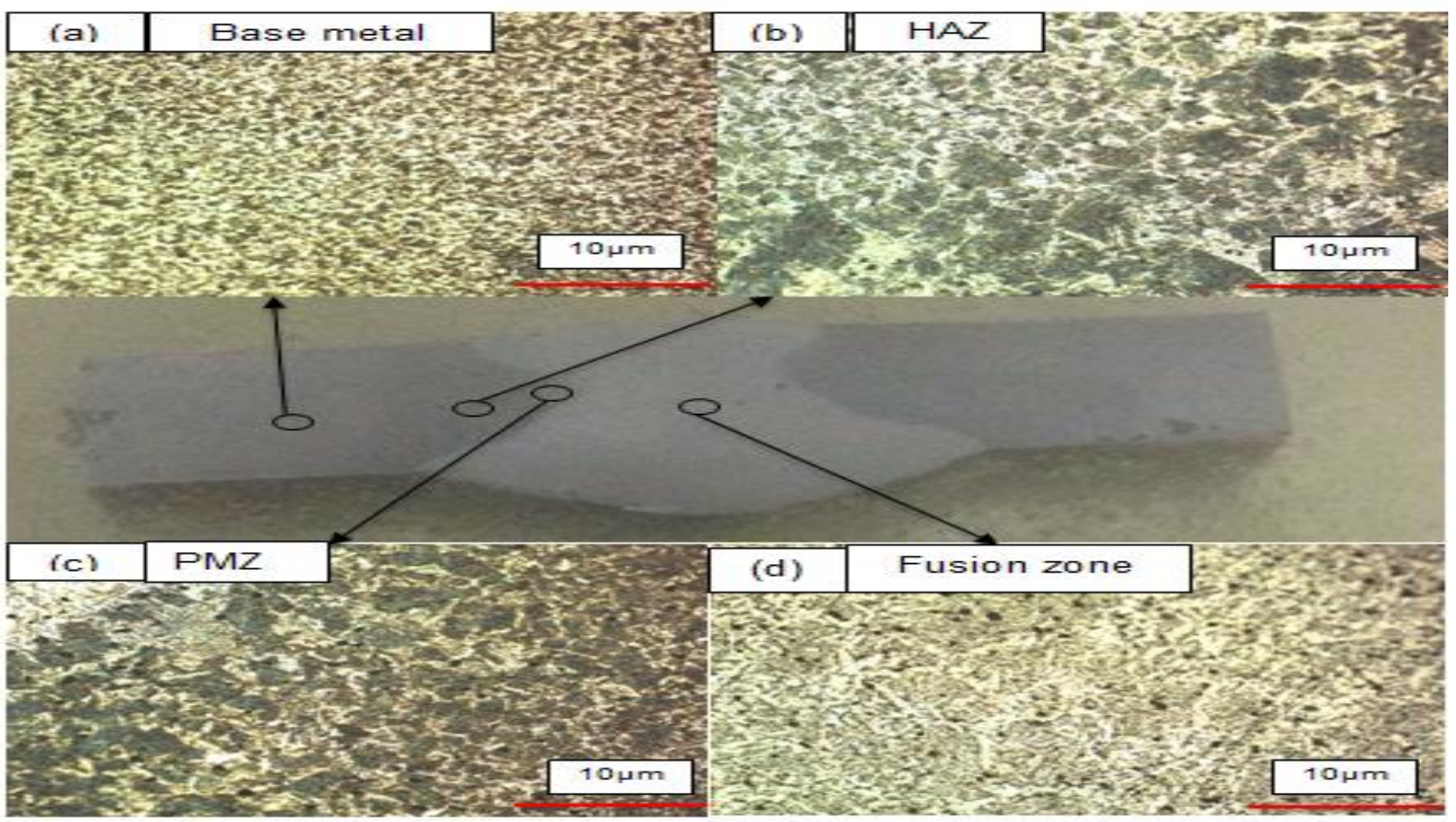

Fig. 8 Microstructure for welded sample using a 1400 gauss magnet applied

The magnetic field exerts force on the electrons and ions within the arc, which causes the arc to be deflected away from the normal path. These are the causes that affect the weldment formation. In this case, when the magnet applied during welding, the welding arc tends to deflect forward, backward, or sideways with respect to electrode and welding direction. These conditions may result deformation on the weld pool surface such as swelling at the bottom part of the weld pool. From the observation, it shows that when applied 1400 gauss magnet, it was found that approximately 5-8mm of molten pool turbulence created during the welding process.

Blue Eyes Intelligence Engineering \& Sciences Publication 


\section{Magnetic Field Effects on 4G Positions in Shielded Metal Arc Welding Process}

In order of using the 1600 gauss magnet,about $10-13 \mathrm{~mm}$ of molten pool turbulence was found created. Meanwhile, when using a 1800 gauss magnet it was found that about $12-15 \mathrm{~mm}$ of molten pool turbulence occurred during welding.

According to the results presented, it can be said that the main factor that cause the turbulence is mainly due to high temperature experienced during welding process. During welding process took place, the metal being welded were locally heated and subjected to high temperature from the arc and the process was influenced by the strength of magnet in the same distance it was applied. Therefore, the welding arc is deflected on sideways with respect to the electrode and welding direction. In addition to that, all the forces acting in the arc zone was suggested to influence on resisting or facilitating the detachment of molten metal from dropping out or hanging at the centre of the weldment.

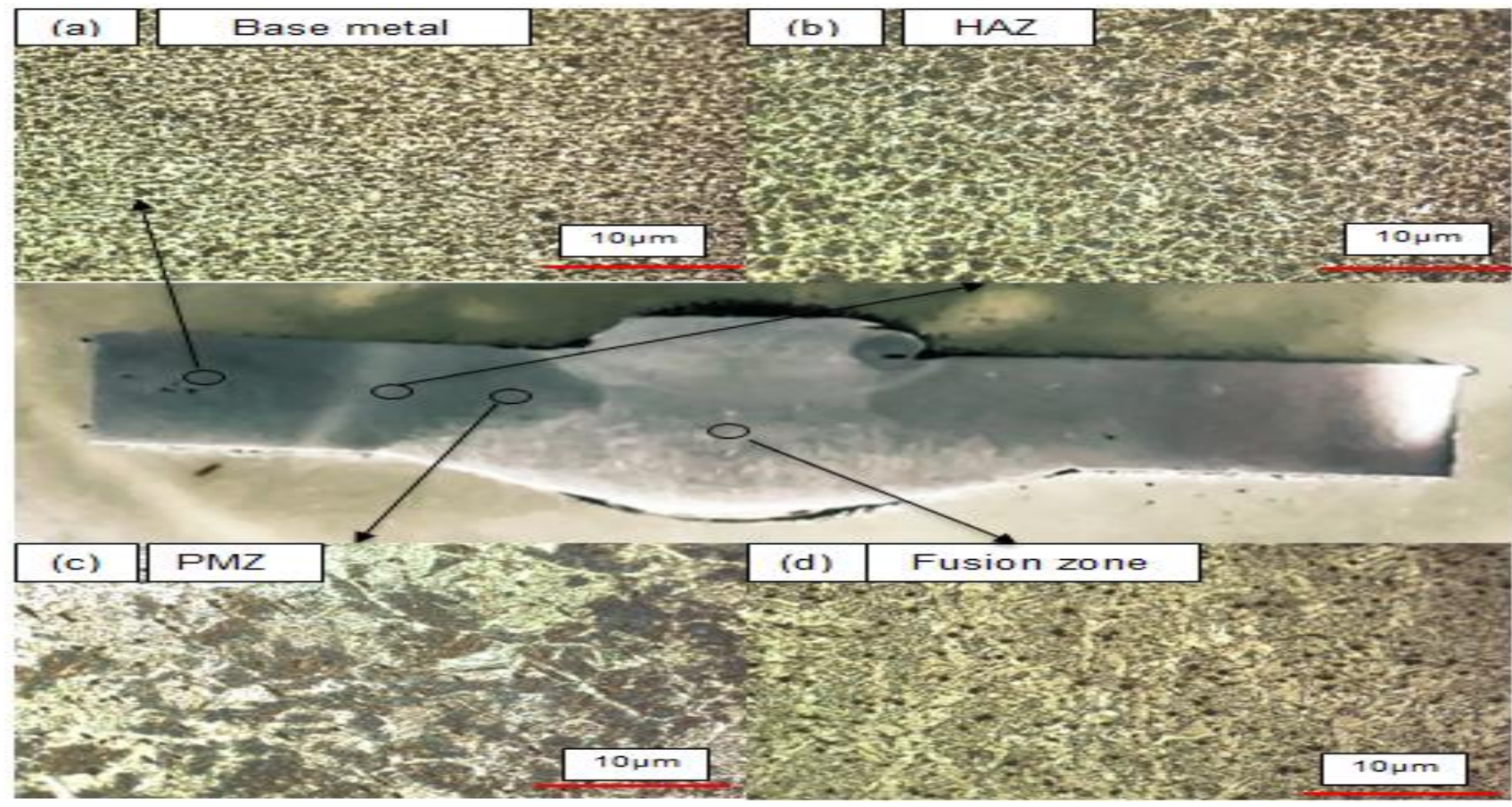

Fig. 9Microstructure for welded sample using a 1600 gauss magnet applied

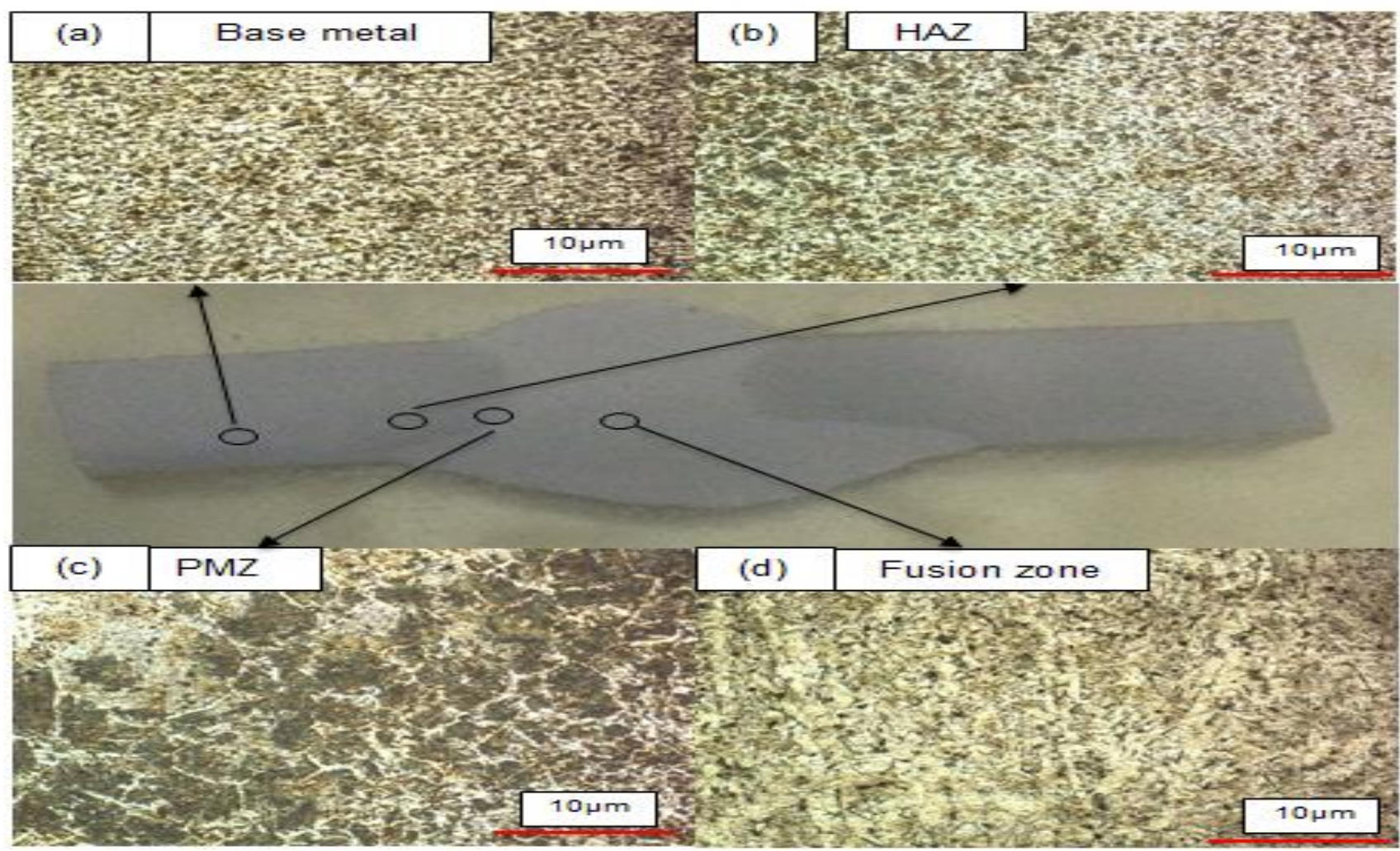

Fig. 10Microstructure for welded sample using a 1800 gauss magnet applied

Published By:
Blue Eyes Intelligence Engineering \& Sciences Publication

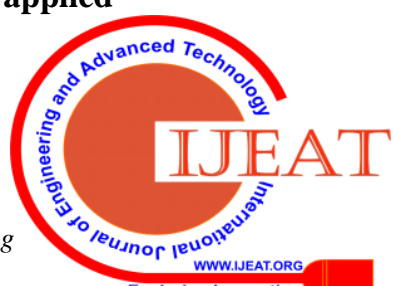




\section{Microstructure Analysis}

Fig. 8 shows microstructure of welded zones of sample using a 1400 gauss magnet applied. It shows that the grain structure of this samples showing a more coarser microstructure pattern in each zone. Due to heat applied it shows that the grain size become larger at the welded zones compared to the base metal. This is due to the area of the base metal being subjected to heat and thus, leads to the grain boundary to change in size. Also the bainite microstructure occurs because of fast cooling rate it may reduce the strength of mechanical properties effect from this strength of magnet used. As indicated in Fig. 8 (d), the fusion zone shows the phase of transformation occurred resulting many type and size of microstructure. It shows that, the use of this magnet strength resulting the grain size slightly smaller and solidification range slightly slower too. It can be said that, the weld solidification become slower because the influence by magnetic field which result to finer grain size microstructure [15].

Fig. 9 and 10 show similar findings as shown in Fig. 8. As indicated in the figures, it shows that the phase of transformation occurred at fusion zone resulting many type and size of microstructure.However, it is relatively harder phase. Based on the results, the grain structures of the metal vary with different of the area observed either base metal, fusion zone or the heat affected zone (HAZ) area. The appearance of ferrite, pearlite and cementite can be clearly seen in Fig. 8 to 10. Ferrite is shown as the light colored and pearlite is the dark colored microstructure.The grain structure at the HAZ area shows that the grain structures are rougher compared with base metal grain structure. The grain structure at the fusion zone area shows different characteristics than the grain structure of the base metal such as the dendritic area. The ferrite regions at fusion zone microstructure are also different. From the result, it can be said that the grain structure of the metal change according to the heat that being applied [16]. The area that received heat greater than the melting temperature will experience the recrystallization of the grain structure.

\section{Tensile Test}

Fig. 11 shows the stress-strain graph that shows three specimens that apply three different strength of ferrite magnet and one specimen without using magnet on base metal during welding process. According to the stress strain graph, the result that was given shows that all specimens had an elastic region of $9 \%$ strain and $280 \mathrm{MPa}$ stress. Below to this point specimens are in elastic region where it can reverse back to the original shape. At point of $10 \%$ of strain and $300 \mathrm{MPa}$ as it shown in Fig. 11, all specimens start to change their line pattern on the graph where the plastic region start to show their act and behavior. At this point, the specimen without magnet being pull only in the range of $10-14 \%$ of strain and after the stress reading reach $460 \mathrm{MPa}$, the specimen start to formed a neck. This is due to the deformation and discontinuity that had on the weldment caused by the hot pass layer of welding that is not fuse completely on the side wall fusion as shown in macrostructure result of this specimen. The result of low strain for this specimen may subject to the slow travel speed during the weld and cause excess in heat input. The high strength achieved for this specimen may result in low ductility behavior.

This situation may suggest that the material experienced hardening characteristics. For specimen that is welded using the aid of a 1400 gauss magnet, the plastic region could withstand in a range between 300-400MPa. This specimen has low strength compared to the other specimens, and shows to have the ultimate tensile strength that reached 390MPa and start to undergo necking process at $370 \mathrm{MPa}$. At this point, the material and local yielding begins and a neck is formed at one point of the specimen. Because of that, this specimen has low strength and high ductility among the other specimens. This is due to the constant travel speed during welding. Meanwhile, for sample that used 1600 gauss magnet during welding, it shows that the value of strength raising from $350 \mathrm{MPa}$ till reach the highest strength which is 535MPa. In this regard, this specimen shows the highest ultimate tensile strength compared to others.

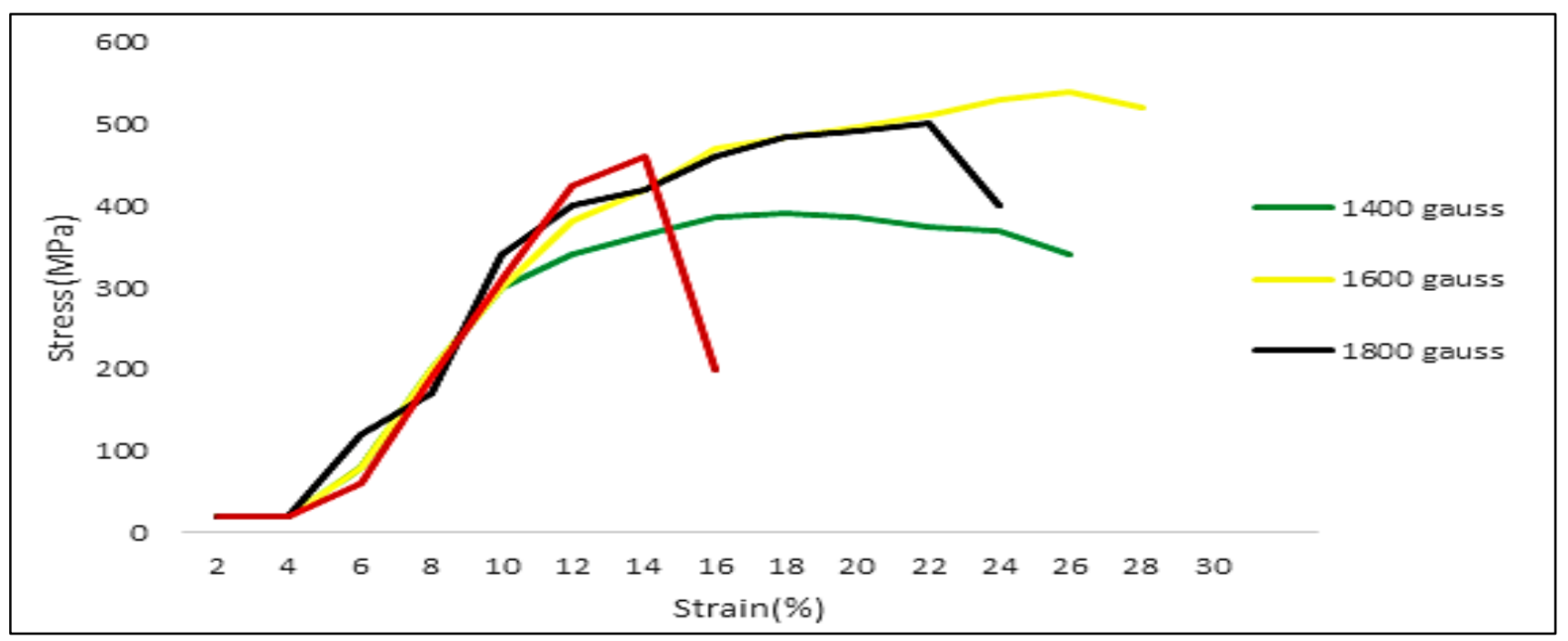

Fig. 11 Stress-strain curve 


\section{Magnetic Field Effects on 4G Positions in Shielded Metal Arc Welding Process}

Because of this result, the specimen is resulting to become more brittle. It also has higher strain reading compared to the other specimen. Because of that, it may result to ductilebehaviour. This is due to the repeated welding and grinding during the welding process. For specimen that was welded using 1800 gauss magnet, the graphs are similar with the findings that shown by the specimen that welded using 1600 gauss magnet. The significant change that can be seen at the value of ultimate tensile strength of this specimen, as it reached 500MPa and 22\% of strain while 1600 gauss specimen reached their ultimate tensile strength at 535MPa at $26 \%$ of strain. The necking process formed earlier compared to the specimen that using a 1600 gauss magnet. Due to local necking, beyond the point of $400 \mathrm{MPa}$, the stress in the material starts decreasing and the specimen breaks at the neck corresponding to stress at point above $22 \%$ strain. The causes of this situation may subject to slag inclusion on the weldment. The high strength of this specimen also caused by the uncontrolled of repeated grinding and welding, and this action may subject to low ductilitybehaviour. It may be avoid by cleaning properly during sample preparation stage, between each layer of the weld and by reducing the amount of grinding between each layer. The proper cleaning method after one to another layer may help to produce a good weld run.

\section{E. BendTest}

Fig. 12 shows a load-extension graph that indicated three specimens that apply three different strength of ferrite magnet and one specimen without magnet on base metal, during welding process. According to the load-extension graph, the result that was given shows that all specimens had an elastic region on $8 \mathrm{~mm}$ of extension while the load ranges between $2 \mathrm{kN}$ to $3.5 \mathrm{kN}$. Below to this point specimens are in elastic region where it can reverse back to the original shape. Specimen without magnet and the specimen that using a 1400 gauss magnet are almost show similar behavior Meanwhile,specimens that used 1600 and 1800 gauss magnet during welding also show similar characteristics and behaviour. The specimen without magnet shows the highest load among the other specimen when it reached $24 \mathrm{~mm}$ of extension. Follow by the 1400 gauss magnet specimen also reach the highest load on the $24 \mathrm{~mm}$ of extension. Furthermore, these two specimensshows the highest load because of defect occurred on the weld such lack of sidewall fusion close to the cap that not fuse completely, it proven on the macrostructure result.

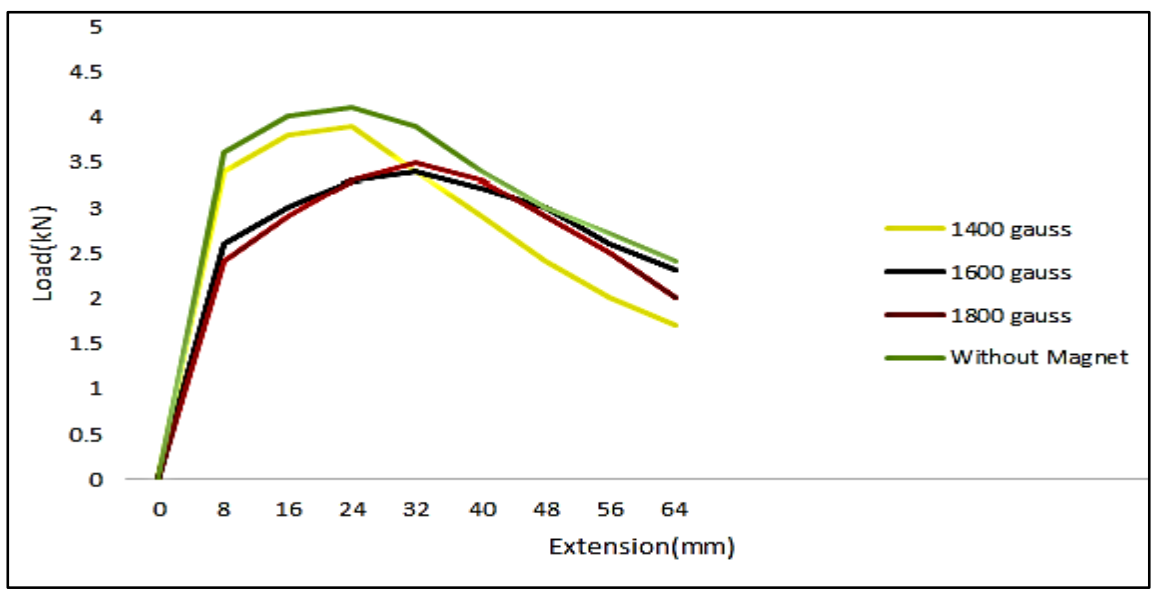

Fig. 12 Load-extension graphs

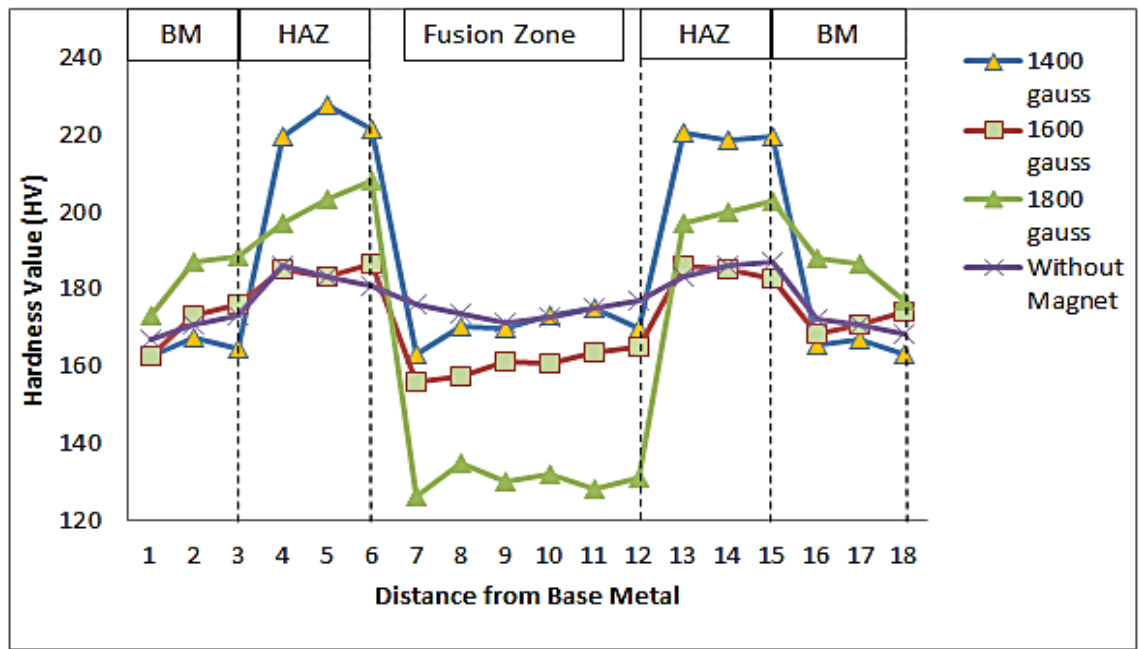

Fig. 13 Hardness value of magnet and without magnet 


\section{F. Hardness}

Fig. 13 shows that the hardness value of four welded specimens that applied with and without and aid of a magnet during welding process. According to the graph, hardness value for base metal is not much affected by the heat applied during welding processin the range between $160-190 \mathrm{HV}$. For sample welded using 1800 gauss magnet, it shows that the specimen indicate the highest hardness value among the others specimen. This is due to high heat input compared to others. The hardness value of specimen without magnet, shows no changes either at the base metal or fusion zone whether it increase or decrease especially on both side of base metal. For 1400 gauss magnet specimen, hardness values on base metal are the one that indicated the lowest hardness value among the other specimens. The result at the both side of base metal shows no clear changes although affected by heat. It can be stated that the magnet strength shows no clear effects on the hardness value especially on specimens without applying magnet during welding.

According to Fig. 13, it shows that HAZ shows high hardness value for all specimens. The highest hardness value indicate that sample that is welded using a 1400 gauss magnet presented a drastic increase. Meanwhile, for specimen that using a 1800 gauss magnet, the HAZ hardness values also reached the second highest hardness value. It is because, during welding process, welding and grinding that apply repeatedly without controlling the amount. This could cause more heat absorbed on the material. It may result the area of brittle failure resistance. This condition can be avoided by controlling the grinding processin order to prevent external heat input.

Overall, all specimens indicated a low hardness value especially at fusion zone area. Specimen that using a 1800 gauss magnet shows the lowest among the others followed by 1600 gauss magnet specimen and then 1400 gauss magnet specimen. The decrease of hardness value from HAZ to fusion zone area is drastically droppedfor specimen using a 1800 gauss magnet and 1400 gauss magnet specimen. This situation may result in high ductilitybehaviour on the weldment. It caused by the amount of ferrite contentin the weldment as shown in the microstructure analysis. The high content of ferrite structure may result to high ductility characteristics. In addition to that, specimen without magnet and 1400 gauss specimen show the similar hardness properties. The difference is only for specimens without magnet that shows the characteristics of HAZ and fusion zone that was found to slightly decrease while 1400 gauss magnet specimen decreases drastically at HAZ. It can be suggested that, specimen without magnet and 1400 gauss magnet specimen can be acceptable based on the hardness value mainly on the fusion zone area.

\section{CONCLUSION}

Welding in overhead position without magnet could be difficult for beginner welder especially in controlling the molten pool behavior. Instead of that, the magnetic field applies are varied. Having an influence of magnetic field in welding process, the material shows an increase in terms of strength, ductility, and hardness. Microstructure show that the grain boundaries for three different magnet presented

good mechanical properties in every aspect. Microstructure shows that the fusions of each specimen that apply and aid by magnet shows to have finer structure except for the HAZ which is more to rough structure. Therefore, in terms of mechanical properties, magnetic field appliesshows better behavior and good properties compared to the specimen that is welded without an aid of a magnet.

\section{REFERENCES}

1. Frank M.Marlow. \& Illustrations by Pamela. (2007). Tallman Welding Essential. New York, NY.

2. Rudy Mohler.(1983). Practical Welding Technology New York, NY

3. Raymond J. Sacks \& Edward R. Bohnart. (2005). Welding Principles and Practices New York

4. William A. Bowditch, Kevin E. Bowditch \& Mark A. Bowditch. (2005). Welding Technology Fundamentals. Illinois

5. D.W. Cho, S.J. Na \& M.H. Cho (2013). A study on V-groove GMAW for various welding positions. Journal of Materials Processing Technology, 213, 1640-1652.

6. Jun Xiong\&Guangjun Zhang (2014). Adaptive Control of Deposited Height in GMAW-Based Layer Additive Manufacturing. Journal of Materials Processing Technology, 214, 962-968

7. R. T. Telford \& F. T. Stanchus (1958) Industrial Applications of Magnetic Flux Gas-Shielded Arc Welding. The Welding Journal

8. Dae-Won Cho \& Suck-Joo Na. (2015). Molten pool behaviours for second pass V-groove GMAW. International Journal of Heat and Mass Transfer, 88, 945-956.

9. S. Kou \& Y. H. Wang. (1986) Weld Pool Convection and Its Effect. app.aws.org/wj/supplement/WJ_1986_03_s63

10. Dae-Won Cho \&DegalaVenkata Kiran (2017). Analysis of Molten Pool Behaviour by Flux-Wall Guided Metal Transfer in Low-Current Submerged Arc Welding. International Journal of Heat and Mass Transfer.

11. Jeff Nadzam. Gas Metal Arc Welding Guidelines.

12. www.lincolnelectric.com/assets/global/Products/Consumable_MIGG MAWWires-SuperArc-SuperArcL-56/c4200

13. Y. Li, C. S Wu \& L. Wang (2015). Analysis of Additional Electromagnetic Force for Mitigating The Humping Bead in High-Speed GMAW. International Journal of Heat and Mass Transfer,100.104-112

14. Sanjay K. Upadhyay\&Kartik K. lyer (2017). Magnetic Behaviors of New Compounds. Journal of Magnetism and Magnetic Materials.

15. Omer W (2000). Structural Welding Code - Steel, United State of America, USA. American National Standards Institute.

16. ZakariaBoumerzoug\&ChemseddinceDerfouf. (2010) Effect of Welding on Microstructure and Mechanical Properties of an Industrial Low Carbon Steel. Engineering, 2, 502-506.

\section{AUTHORS PROFILE}

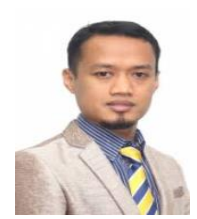

Muhamad Hellmy Hussin, is a lecturer in University of Kuala Lumpur Malaysia France Institute (UNIKL MFI) located at Bandar BaruBangi, Selangor for fourteen years. His expertise is in Innovation and Engineering Design, and also in Corrosion and Failure Analysis. He did his Bac. (Hons.) in Industrial Production Management at the University Nice Sophie Antipolis (UNSA), France, and then pursued his Master Degree in Innovation and Engineering Design at University of Putra Malaysia (UPM) Serdang, Selangor.Over the last eight years he becomes involved in welding and joining research works. And since then he has continued his research and involved in Corrosion and Failure Analysis research areas, Corrosion and failure analysis works. Now, he pursue his $\mathrm{PhD}$ in (Mechanical), focusing on High Temperature Corrosion in Hot Gases Environment. He has published articles and journals mainly in Welding and Joining, Corrosion degradation and Failure Analysis research works. 
Magnetic Field Effects on 4G Positions in Shielded Metal Arc Welding Process

Dr. NurAzida CheLah, is a senior lecturer on Corrosion degradation and Failure Analysis studies at the University of Kuala Lumpur Malaysia France Institute (UNIKL MFI), Bandar BaruBangi, Selangor. She did her Bac (Hons) in Materials Science and then pursued her Master degree in Mechanical Engineering majoring in Fatigue failure Assessment on welded joint at University of Putra Malaysia (UPM) Serdang, Selangor. Her PhD focusing on High Temperature Corrosion Study on Aluminium Welded Joint at The National University of Malaysia (UKM), Bangi, Selangor. And since 2007 she started writing an articles and journals mostly on Fatigue Assessment Analysis, Welding and Joining, Corrosion degradation and Failure Analysis Studies. 